\title{
GMR
}

Short Communication

\section{Prevalence of thymidylate synthase gene 5'-untranslated region variants in an Argentinean sample}

\author{
C. Vázquez ${ }^{1}$, M. Orlova ${ }^{1}$, P. Scibona ${ }^{1}$, H. Díaz Arce ${ }^{2}$, M.G. Pallotta ${ }^{3}$ and \\ W.H. Belloso ${ }^{1}$
}

${ }^{1}$ Clinical Pharmacology Section, Internal Medicine Service, Hospital Italiano de Buenos Aires, Buenos Aires, Argentina ${ }^{2}$ Molecular Biology Section, Central Laboratory,

Hospital Italiano de Buenos Aires, Buenos Aires, Argentina ${ }^{3}$ Clinical Oncology Section, Internal Medicine Service,

Hospital Italiano de Buenos Aires, Buenos Aires, Argentina

Corresponding author: C. Vázquez

E-mail: carolina.vazquez@hospitalitaliano.org.ar

Genet. Mol. Res. 16 (1): gmr16019367

Received September 22, 2016

Accepted November 18, 2016

Published January 23, 2017

DOI http://dx.doi.org/10.4238/gmr16019367

Copyright (C) 2017 The Authors. This is an open-access article distributed under the terms of the Creative Commons Attribution ShareAlike (CC BY-SA) 4.0 License.

ABSTRACT. Thymidylate synthase (TYMS) is a key enzyme in nucleotide synthesis and therefore, an important target of many chemotherapeutic agents. Expression of TYMS mRNA is thought to be modulated by a $28-\mathrm{bp}$ tandem repeat polymorphism within its 5 '-untranslated region, raising the question of this variant's utility in predicting the efficacy and toxicity of cancer treatment regimens. The aim of the present research was to describe the distribution of this TYMS polymorphism in the Argentinean population. A total of 199 randomly

Genetics and Molecular Research 16 (1): gmr16019367 
selected DNA samples from healthy volunteers were analyzed using polymerase chain reaction and polyacrylamide gel electrophoresis. The $2 \mathrm{R}$ and $3 \mathrm{R}$ alleles were present in 47.74 and $52.26 \%$ of samples, respectively, with frequencies of 21.6 (43), 52.3 (104), and 26.1\% (52) recorded for the $2 R / 2 R, 2 R / 3 R$, and $3 R / 3 R$ genotypes, respectively. No significant difference regarding gender was observed. Our prevalence data are similar to those reported for other Caucasian populations. This opens a discussion concerning the reference population valid for comparisons and the clinical importance of this genotyping test as an additional tool in personalized medicine.

Key words: Thymidylate synthase; TYMS; Pemetrexed; 5-Fluorouracil; Pharmacogenomics

\section{INTRODUCTION}

Thymidylate synthase (TYMS) is a key enzyme in nucleotide synthesis. It catalyzes the conversion of deoxyuridine monophosphate to deoxythymidine monophosphate (dTMP) through a methylation process. This TYMS-dependent reaction is the only source of dTMP in cells. Given its essential role in DNA replication, TYMS is an important direct and indirect target of many chemotherapeutic agents, including 5-fluorouracil and pemetrexed (Ulrich et al., 2000).

The mRNA expression of the TYMS gene is thought to be affected by a 28 -bp tandem repeat polymorphism within its 5'-untranslated region (UTR; Kaneda et al., 1987). The majority of human TYMS alleles harbor either a double (2R) or a triple repeat (3R), resulting in the genotypes $2 R / 2 R, 2 R / 3 R$, and $3 R / 3 R$. Although there have been reports of four- and five-repeat variants in some populations, their global prevalence is very low (Marsh et al., 1999).

Individuals harboring the $3 \mathrm{R} / 3 \mathrm{R}$ genotype may express TYMS at higher levels than those carrying the $2 \mathrm{R} / 2 \mathrm{R}$ genotype (Horie et al., 1995). In addition, a $\mathrm{C} / \mathrm{G}$ single nucleotide polymorphism (SNP) in the second repeat of the $3 \mathrm{R}$ allele has been described, the variants of which are named $3 \mathrm{RC}$ and $3 \mathrm{RG}$. The $3 \mathrm{RC}$ variant may attenuate the increased transcription caused by the presence of three repeats.

Although the exact mechanism responsible is not well understood, it has been postulated that two upstream stimulating factor (USF) family E-box consensus sequences are found within the tandem repeats of the $3 R$ allele. USF proteins bind to these regions, enhancing transcription, and the C/G SNP influences this interaction (Mandola et al., 2003).

The clinical impact of these genotypes may involve both the toxicity and efficacy of chemotherapy. Basic knowledge of the distribution of these polymorphic variants in our country and region is needed, as no data regarding TYMS genotype frequencies in the Argentinean population has been reported to date. Our aim was to describe the frequency of TYMS 5'-UTR variable number tandem repeat (VNTR) polymorphisms in a sample of this population.

\section{MATERIAL AND METHODS}

\section{Study population}

Two hundred and two random samples from healthy controls were retrieved from

Genetics and Molecular Research 16 (1): gmr16019367 
the Hospital Italiano de Buenos Aires DNA Bank and analyzed. Informed consent from participants and approval from the appropriate institutional review boards were obtained.

\section{Sample collection and DNA extraction}

Following obtainment of informed consent, $10 \mathrm{~mL}$ peripheral blood was collected from each subject in 5-mL tubes containing ethylenediaminetetraacetic acid. Whole blood samples were stored at $4^{\circ} \mathrm{C}$ until use. Genomic DNA was extracted and purified using a QIAmp DNA Blood Mini kit (QIAGEN, Hilden, Germany).

\section{Genotyping of TYMS 5'-UTR polymorphism}

Genotyping of the TYMS 5'-UTR polymorphism (rs45445694 in the reference sequence GenBank accession No. NM_001012716.2) was performed by polymerase chain reaction (PCR) and polyacrylamide gel electrophoresis. In each reaction, genomic DNA was amplified using the same primers specific to the TYMS 5'-UTR region (forward, 5'-AGGCGCGCGGAAGGGGTCCT-3'; and reverse, 5'-TCCGAGCCGGCCACAGGCAT-3'; IDT, Coralville, IA, USA), yielding amplicons of 113 and $141 \mathrm{bp}$ for the $2 \mathrm{R} / 2 \mathrm{R}$ and $3 \mathrm{R} / 3 \mathrm{R}$ genotypes, respectively (Kawakami and Watanabe, 2003).

Each PCR comprised a 50- $\mu \mathrm{L}$ mixture containing 1X PCR buffer (Invitrogen, Carlsbad, CA, USA), $1.5 \mathrm{mM}$ magnesium chloride (Invitrogen), $200 \mu \mathrm{M}$ deoxynucleotides (Sigma, St. Louis, MO, USA), $500 \mathrm{nM}$ each primer, $1.5 \mathrm{U}$ Taq polymerase (Invitrogen), 1X betaine (QIAGEN), and $100 \mathrm{ng}$ genomic DNA. Reactions were performed in an Applied Biosystems (Foster City, CA, USA) thermocycler. Cycling parameters for amplification of the TYMS 5'-UTR region were as follows: initial denaturation at $95^{\circ} \mathrm{C}$ for $15 \mathrm{~min}$, then 30 cycles of $91^{\circ} \mathrm{C}$ for $1 \mathrm{~min}, 60^{\circ} \mathrm{C}$ for $1 \mathrm{~min}$, and $72^{\circ} \mathrm{C}$ for $1 \mathrm{~min}$, before a final extension step at $72^{\circ} \mathrm{C}$ for $10 \mathrm{~min}$. Samples were subsequently held at $4^{\circ} \mathrm{C}$ until needed.

In order to characterize amplicons, DNA fragments of all expected sizes from homozygous samples were submitted to an external laboratory (Macrogen, Korea) for purification and sequencing. Sequence quality was analyzed manually using the program Chromas 1.56 (http://www.technelysium.com.au/chromas.html), and each sequence was compared for similarity with others deposited in the GenBank database using the Basic Local Alignment Search Tool on the National Center for Biotechnology Information website (http:// www.ncbi.nlm.nih.gov).

Aliquots of PCR products were electrophoresed on an $8 \%$ polyacrylamide gel and stained with ethidium bromide. DNA bands were visualized with an ultraviolet transilluminator to carry out TYMS 5'-UTR genotyping (Figure 1).

\section{Statistical analysis}

Allelic and genotypic frequencies are reported as absolute values and percentages of the study sample. Two hundred samples were used to estimate $2 \mathrm{R} / 2 \mathrm{R}$ genotype prevalence, previously reported as $19 \%$ in the European population, with a precision of 5.4\% (Marsh et al., 1999). The results obtained were further evaluated for stratification by gender and conformance with Hardy-Weinberg equilibrium. We used Stata v14.1 (StataCorp, College Station, TX, USA) for all analyses.

Genetics and Molecular Research 16 (1): gmr16019367 


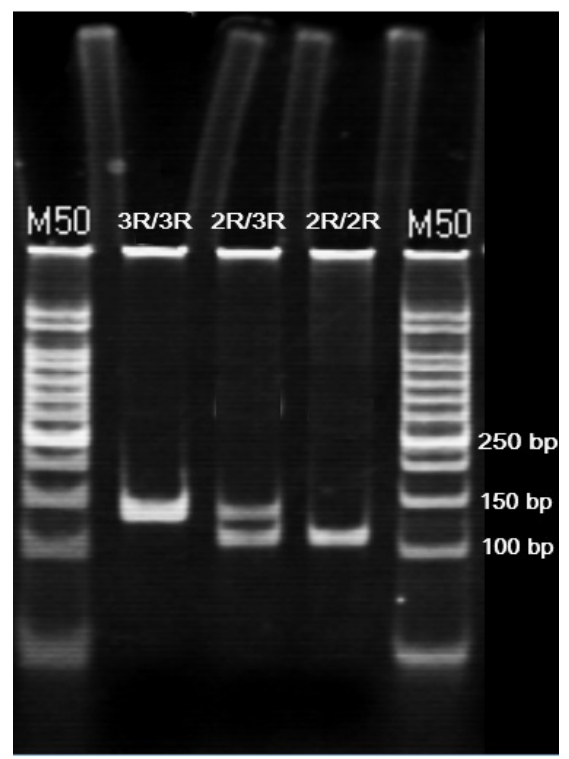

Figure 1. Genotyping of thymidylate synthase 5'-untranslated region variants by polymerase chain reaction and electrophoresis on an $8 \%$ polyacrylamide gel stained with ethidium bromide. A 141-bp band corresponding to the 3R/3R genotype, two bands of 141 and $113 \mathrm{bp}$ signifying the 2R/3R heterozygous genotype, and a 113-bp band resulting from the $2 \mathrm{R} / 2 \mathrm{R}$ genotype are shown. A $50-\mathrm{kb}$ reference ladder is visible to the right and left of the sample lanes.

\section{RESULTS}

We attempted to genotype all samples according to the method described above. Of the 202 subjects analyzed, only 199 were genotyped due to technical problems with the remaining samples. Regarding the demographic characteristics of our sample of healthy volunteers, 106 (53.3\%) were men and $93(46.7 \%)$ were women; the median age was 42 years, with a $25-75 \%$ interquartile range of 33-43 years.

In our study sample, 2R and 3R allele counts were 190 (47.74\%) and $208(52.26 \%)$, respectively, and no $4 \mathrm{R}$ variant was identified. Genotype counts were as follows: $2 \mathrm{R} / 2 \mathrm{R}, 43$ (21.6\%); 2R/3R, 104 (52.3\%); 3R/3R, 52 (26.1\%).

Concerning stratification of the data by sex, the following distribution of genotypes was observed among women: 2R/2R, 21 (22.6\%); 2R/3R, $49(52.7 \%) ; 3 \mathrm{R} / 3 \mathrm{R}, 23(24.7 \%)$. That among men was as follows: 2R/2R, $22(20.8 \%) ; 2 \mathrm{R} / 3 \mathrm{R}, 55(51.9 \%) ; 3 \mathrm{R} / 3 \mathrm{R}, 29(27.3 \%)$. The difference between the male and female groups was not significant based on a two-sided Fisher's exact test $(\mathrm{P}=0.89)$.

The distributions were also analyzed for Hardy-Weinberg equilibrium. The expected genotype frequencies were $2 \mathrm{R} / 2 \mathrm{R}, 45.4 ; 2 \mathrm{R} / 3 \mathrm{R}, 99.3$; and $3 \mathrm{R} / 3 \mathrm{R}, 54.4$. A P-value of 0.5 was returned from a two-sided chi-square test with one degree of freedom, failing to reject the null hypothesis of a population in equilibrium.

\section{DISCUSSION}

To our knowledge, this is the first report of the prevalence of TYMS 5'-UTR variants 
in an Argentinean population sample. The functional effects of this polymorphism have been analyzed previously in many in vitro and in vivo contexts. Compared with the $3 \mathrm{RG} / 3 \mathrm{RG}$ genotype, the $2 \mathrm{R} / 2 \mathrm{R}, 2 \mathrm{R} / 3 \mathrm{RC}$, and $2 \mathrm{R} / 3 \mathrm{RG}$ variants are associated with lower intratumoral TYMS mRNA levels (Morganti et al., 2005).

In terms of the possible clinical impact of this phenomenon, studies of germline carriers of these variants have shown that compared with high-expression genotypes $(2 \mathrm{R} / 3 \mathrm{RG}$, $3 R G / 3 R C$, and $3 R G / 3 R G)$, those resulting in lower TYMS expression $(2 R / 2 R, 2 R / 3 R C$, and $3 \mathrm{RC} / 3 \mathrm{RC}$ ) are associated with better 5-fluorouracil response in liver-only metastatic colorectal cancer (Graziano et al., 2008). Moreover, in comparison with the $2 \mathrm{R} / 3 \mathrm{R}$ and $2 \mathrm{R} / 2 \mathrm{R}$ variants, the $3 \mathrm{R} / 3 \mathrm{R}$ genotype has been linked to greater overall response rate, overall survival, and a tendency for increased progression-free survival in wild-type epidermal growth factor receptor patients with non-small cell lung cancer (NSCLC) receiving pemetrexed (Arévalo et al., 2014).

Germline carriers of the TYMS 2R/2R genotype are at increased risk of severe diarrhea when treated with 5-fluorouracil, compared to those with the $2 \mathrm{R} / 3 \mathrm{R}$ or $3 \mathrm{R} / 3 \mathrm{R}$ genotype (Lecomte et al., 2004; Schwab et al., 2008). In contrast, grade 3-4 hematologic toxicities are more frequent among Japanese carriers of the 3R/3R genotype with NSCLC treated with pemetrexed in combination with carboplatin (Kanazawa et al., 2014).

Concerning tumorigenesis, a meta-analysis carried out by Wang et al. (2014) revealed that the $2 \mathrm{R} / 3 \mathrm{R}$ and $2 \mathrm{R} / 2 \mathrm{R}$ genotypes confer a lower risk of developing colorectal cancer among Caucasians. However, no association has been established between the TYMS 5'-UTR VNTR polymorphism and the incidence of gastric tumors, breast cancer, or leukemia (Nazki et al., 2012; Quintero-Ramos et al., 2014; Araújo et al., 2015).

Given its links to chemotherapy efficacy and toxicity and tumorigenesis, further pharmacogenetic research involving this particular TYMS polymorphism is warranted in the context of oncology. The present study constitutes the first study of TYMS 5'-UTR VNTR polymorphism prevalence in an Argentinean population sample. The allelic and genotypic frequencies recorded here were similar to those previously reported by Marsh et al. (1999), who found the $2 \mathrm{R} / 2 \mathrm{R}, 2 \mathrm{R} / 3 \mathrm{R}$, and $3 \mathrm{R} / 3 \mathrm{R}$ genotypes to be present in 19,43 , and $38 \%$ of a Caucasian population represented by 96 samples.

One limitation of the present study should be addressed. We did not genotype the $\mathrm{C} / \mathrm{G}$ SNP in the second repeat of the $3 \mathrm{R}$ allele, yet this variation may be important in determining the efficacy and toxicity of certain drugs, as described above.

The comparability of our findings with those of other studies of the prevalence of this polymorphism may be due to the genetic backgrounds of the populations considered. The contemporary Argentinian population is thought to include components of European, Native American, and African genetic ancestry, but in relative proportions appear to depend on the genetic material considered. Argentines carry a large fraction of their European genetic heritage in their Y chromosomal (94.1\%) and autosomal (78.5\%) DNA, but their mitochondrial gene pool is mostly of Native American ancestry (53.7\%). However, the African contribution is small in all three genetic systems ( $<4 \%$; Corach et al., 2010). This large European element in the autosomal genome may in part account for the similarity between our results and previously reported frequencies based on Caucasian samples.

Our investigation provides additional data useful to future research concerning the TYMS 5'-UTR polymorphism in Argentina and other countries with similar genetic ancestry. This benefits studies of the efficacy and toxicity of the many chemotherapeutic agents targeting the TYMS enzyme, as well as tumorigenesis research, where a particular patient group may be

Genetics and Molecular Research 16 (1): gmr16019367 
compared with healthy controls and/or the general population in relation to the prevalence of this polymorphism in a country and/or region.

\section{Conflicts of interest}

The authors declare no conflict of interest.

\section{ACKNOWLEDGMENTS}

We are very grateful to Instituto de Ciencias Básicas y Medicina Experimental (ICBME) at Hospital Italiano de Buenos Aires for the provision of DNA samples. Instituto Nacional Del Cáncer, Argentina, funded the genotyping. The funding bodies had no role in study design, data collection or analysis, decision to publish, or manuscript preparation.

\section{REFERENCES}

Araújo MD, Borges BN, Rodrigues-Antunes S, Burbano RM, et al. (2015). Thymidylate synthase and methylenetetrahydrofolate reductase gene polymorphisms and gastric cancer susceptibility in a population of Northern Brazil. Genet. Mol. Res. 14: 10001-10006. http://dx.doi.org/10.4238/2015.August.21.6

Arévalo E, Castañón E, López I, Salgado J, et al. (2014). Thymidylate synthase polymorphisms in genomic DNA as clinical outcome predictors in a European population of advanced non-small cell lung cancer patients receiving pemetrexed. J. Transl. Med. 12: 98. http://dx.doi.org/10.1186/1479-5876-12-98

Corach D, Lao O, Bobillo C, van Der Gaag K, et al. (2010). Inferring continental ancestry of argentineans from Autosomal, Y-chromosomal and mitochondrial DNA. Ann. Hum. Genet. 74: 65-76. http://dx.doi.org/10.1111/j.14691809.2009.00556.x

Graziano F, Ruzzo A, Loupakis F, Santini D, et al. (2008). Liver-only metastatic colorectal cancer patients and thymidylate synthase polymorphisms for predicting response to 5-fluorouracil-based chemotherapy. Br. J. Cancer 99: 716-721. http://dx.doi.org/10.1038/sj.bjc.6604555

Horie N, Aiba H, Oguro K, Hojo H, et al. (1995). Functional analysis and DNA polymorphism of the tandemly repeated sequences in the 5'-terminal regulatory region of the human gene for thymidylate synthase. Cell Struct. Funct. 20: 191-197. http://dx.doi.org/10.1247/csf.20.191

Kanazawa K, Yokouchi H, Wang X, Ishida T, et al.; Hokkaido Lung Cancer Clinical Study Group (2014). Phase II trial of carboplatin and pemetrexed as first-line chemotherapy for non-squamous non-small cell lung cancer, and correlation between the efficacy/toxicity and genetic polymorphisms associated with pemetrexed metabolism: Hokkaido Lung Cancer Clinical Study Group Trial (HOT) 0902. Cancer Chemother. Pharmacol. 74: 1149-1157. http://dx.doi. org $/ 10.1007 / \mathrm{s} 00280-014-2589-3$

Kaneda S, Takeishi K, Ayusawa D, Shimizu K, et al. (1987). Role in translation of a triple tandemly repeated sequence in the 5'-untranslated region of human thymidylate synthase mRNA. Nucleic Acids Res. 15: 1259-1270. http://dx.doi. org $/ 10.1093 /$ nar $/ 15.3 .1259$

Kawakami K and Watanabe G (2003). Identification and functional analysis of single nucleotide polymorphism in the tandem repeat sequence of thymidylate synthase gene. Cancer Res. 63: 6004-6007.

Lecomte T, Ferraz JM, Zinzindohoué F, Loriot MA, et al. (2004). Thymidylate synthase gene polymorphism predicts toxicity in colorectal cancer patients receiving 5-fluorouracil-based chemotherapy. Clin. Cancer Res. 10: 5880-5888. http://dx.doi.org/10.1158/1078-0432.CCR-04-0169

Mandola MV, Stoehlmacher J, Muller-Weeks S, Cesarone G, et al. (2003). A novel single nucleotide polymorphism within the 5 ' tandem repeat polymorphism of the thymidylate synthase gene abolishes USF-1 binding and alters transcriptional activity. Cancer Res. 63: 2898-2904.

Marsh S, Collie-Duguid ES, Li T, Liu X, et al. (1999). Ethnic variation in the thymidylate synthase enhancer region polymorphism among Caucasian and Asian populations. Genomics 58: 310-312. http://dx.doi.org/10.1006/ geno.1999.5833

Morganti M, Ciantelli M, Giglioni B, Putignano AL, et al. (2005). Relationships between promoter polymorphisms in the thymidylate synthase gene and mRNA levels in colorectal cancers. Eur. J. Cancer 41: 2176-2183. http://dx.doi. org/10.1016/j.ejca.2005.06.016

Genetics and Molecular Research 16 (1): gmr16019367 
Nazki FH, Masood A, Banday MA, Bhat A, et al. (2012). Thymidylate synthase enhancer region polymorphism not related to susceptibility to acute lymphoblastic leukemia in the Kashmir population. Genet. Mol. Res. 11: 906-917. http:// dx.doi.org/10.4238/2012.April.10.6

Quintero-Ramos A, Gutiérrez-Rubio SA, Del Toro-Arreola A, Franco-Topete RA, et al. (2014). Association between polymorphisms in the thymidylate synthase gene and risk of breast cancer in a Mexican population. Genet. Mol. Res. 13: 8749-8756. http://dx.doi.org/10.4238/2014.October.27.16

Schwab M, Zanger UM, Marx C, Schaeffeler E, et al.; German 5-FU Toxicity Study Group (2008). Role of genetic and nongenetic factors for fluorouracil treatment-related severe toxicity: a prospective clinical trial by the German 5-FU Toxicity Study Group. J. Clin. Oncol. 26: 2131-2138. http://dx.doi.org/10.1200/JCO.2006.10.4182

Ulrich CM, Bigler J, Velicer CM, Greene EA, et al. (2000). Searching expressed sequence tag databases: discovery and confirmation of a common polymorphism in the thymidylate synthase gene. Cancer Epidemiol. Biomarkers Prev. 9: $1381-1385$.

Wang J, Shi D, Guo X, Zhang J, et al. (2014). Thymidylate synthase genetic polymorphisms and colorectal cancer risk: a meta-analysis. Clin. Res. Hepatol. Gastroenterol. 38: 481-490. http://dx.doi.org/10.1016/j.clinre.2014.02.006

Genetics and Molecular Research 16 (1): gmr16019367 